\title{
Cidadania e judicialização dos conflitos sociais
}

João Luiz Martins Esteves

\section{Resumo}

Com o objetivo de fornecer uma proposta para efetivação dos direitos sociais no Brasil, procede uma análise do desenvolvimento político e jurídico da categoria "cidadania" e mostra sua relação com a concepção de "classe social", identificando a trajetória da declaração e consolidação dos direitos fundamentais. Verificam-se seqüencialmente, os motivos que levam a uma migração, para o campo jurídico, das demandas relativas à efetivação dos direitos sociais nos países em que ainda não se consolidaram, tendo como foco de atenção o Brasil. Por fim, aponta para os rumos a serem tomados pelo judiciário frente a essas novas exigências.

Palavras Chave: Cidadania; Direitos Sociais; Poder Judiciário.

\section{Introdução}

Desde a edição da Constituição Federal de 1988, particularmente no âmbito da jurisdição constitucional, através do controle concreto ou abstrato das leis, tem sido comum a busca da sociedade pela efetivação dos direitos sociais.

Através de uma visão do panorama geral das atividades desenvolvidas para esta efetivação é possível enxergar que os sindicatos, as organizações sociais não governamentais, além do próprio cidadão de maneira individual, depois de uma série de batalhas no âmbito político, passaram a procurar, através do ingresso de ações judiciais, um posicionamento do Poder Judiciário quanto à garantia e efetivação daqueles direitos.

Este fenômeno, tem sido chamado no mundo acadêmico, de "judicialização dos conflitos sociais", ou em uma amplitude que revele a problematização da atividade política, "judicialização da política" a qual, muitas das vezes, trás nela embutidas questões de ordem social.

Analisar e concluir sobre os resultados e conseqüências deste fenômeno é o que nos propomos nas linhas que se seguem, fazendo uma proposição que não tem o interesse de ser conclusiva, mas pretende contribuir para o debate que vem sendo desenvolvido sobre a questão apresentada. 


\section{Cidadania}

No âmbito do estudo do direito no Brasil, e particularmente no direito constitucional, a categoria cidadania tem carregado uma identificação que a confunde com o exercício dos direitos políticos. Ferreira Filho (1995, p. 99) identifica a cidadania como um "status ligado ao regime político". Fazendo uma análise sobre qual nacional (aquele que não é estrangeiro) detém cidadania, cita o exemplo do analfabeto

Veja-se o caso do analfabeto, que inscrito como eleitor, se torna cidadão ativo, mas não se pode tornar cidadão passivo, por não ter elegibilidade. (FERREIRA FILHO, 1995, p. 99)

Sendo assim, conforme esta doutrina, comum e presente na grande maioria dos manuais de direito constitucional no Brasil, o analfabeto não é cidadão. Isto deve-se ao fato de ter-se reduzido a cidadania à questão de caráter político-representativo, como modelo de positivação da ordem capitalista vigente.

Este discurso apresenta-se como caracterizador de uma cultura jurídica dominante, lógico-formalista de inspiração liberal, que tem por objetivo estruturar as categorias, que a princípio são político-sociológicas, em esquemas normativos regulatórios que as definam ideológicamente e impossibilitem uma maior amplitude ou a construção de uma trajetória de compreensão do seu significado. Enquadrar a categoria de cidadania em uma definição reduzida e hermética não parece outra coisa senão, retirar-lhe conteúdo e amoldá-la a um concepção de estado, ao qual pretende-se que fique presa.

É necessária uma redefinição, ou um resgate do real significado da cidadania em termos constitucionais, que supere a lógica-formalista vinculada ao ideário liberal o qual ainda faz-se sentir presente no ensino do direito realizado no país. Esta afirmativa, não é feita somente com o objetivo de contestar ideologicamente o modelo de ensino existente e a ordem poítico-econômica no qual se fundou. Traduz sim, uma preocupação em investigar e compreender a ocorrência de certos fenômenos da sociedade contemporânea, particularmente em terras brasileiras, derivados de uma elevação do grau de compreensão política desenvolvido a partir da edição da Constituição de 1988. Esta tomada de consciência política pode ser constatada a partir da verificação da montagem de milhares de associações civis nos últimos quinze anos, que se movimentam no sentido de reivindicar e garantir os 
direitos fundamentais proclamados não somente na Constituição, mas também outros derivados de uma esfera internacional. Esta movimentação tem passado por diversos estágios, chegando na atualidade a uma exigência que se faz em relação ao Poder Judiciário, de garantidor e efetivador desses direitos, processo este o qual tem-se denominado de "judicialização dos conflitos sociais".

Para isso o estudo desenvolvido por Marshal (1967) em sua clássica obra, Cidadania, Classe Social e Status, apresenta-se como de fundamental importância para que fixe-se o alcance e desenvolvimento da cidadania. $O$ autor, analisando a sociedade européia, e particularmente a inglesa, resgata este conceito desde a fundação da categoria, traça uma trajetória do seu significado e alcance, desde o século XVIII até o século XX.

Define a existência de três elementos essenciais do conceito de cidadania, o civil, o político e o social (MARSHAL, 1967, p.63), que sendo confundidos durante a idade média, distanciam-se a partir da formação do estado liberal, podendo atribuir-se períodos de formação independente de cada um deles, levando-se em conta um entrelaçamento: a) os direitos civis no século XVIII; b) os políticos no século XIX; e c) os direitos sociais no século XX (MARSHAL, 1967, p. 66).

A cidadania, portanto, inicialmente é declarada como resultante da aquisição dos direitos civis, que são aqueles do indivíduo, e sobre esta noção desenvolveu-se inicialmente. E apesar de identificados no século XVIII, em análise que possamos realizar da história do desenvolvimento do estado liberal foi, no século XIX, que deu-se o marco da consolidação e reconhecimento desses direitos na maioria dos países. Por sua vez, os direitos políticos, tratados inicialmente como produto secundário dos direitos civis, somente adquirirão posição de independência em relação à cidadania no século XX (MARSHAL, 1967, p.70).

Também, os direitos sociais universalizaram-se durante o transcorrer do século XX, e particularmente ganharam dimensão de importância permanente e por vezes superior aos direitos individuais a partir da segunda metade do século $X X$, identificado-se com o surgimento do estado de bem estar social e a consolidação desses próprios direitos em termos constitucionais, doutrinários e jurisprudenciais, passando a ser efetivamente reconhecidos e reclamados por setores organizados da sociedade contemporânea. 
Sem receio, podemos identificar a partir da consolidação dos direitos sociais, também o surgimento dos direitos difusos e coletivos, onde o direito ambiental apresenta-se como propulsor dessa nova categoria de direitos que encontra-se em fase de consolidação.

Ao analisar a trajetória do desenvolvimento da cidadania, Marshal não abandona a categoria existente de classe social. Pelo contrário procura identificar a existência de antagonismos e congruências entre estas duas categorias, a cidadania e classe social.

O conceito de classe social, iniciado a partir de Marx ${ }^{1}$, revela a existência da propriedade dos meios de produção pertencentes a uma elite que, aproveitando-se da mão de obra dos não proprietários, apropria-se também do resultado do trabalho por eles realizado. Na sociedade capitalista esta elite proprietária, denominada burguesia, formada a partir do surgimento do próprio sistema, confronta-se com os reais produtores da mercadoria, o proletariado, que despojado do fruto de seu trabalho, passa a realizar reivindicações através de organizações associativas criadas a partir do século XIX.

São por estas reivindicações, travadas através de lutas políticas e econômicas, que os direitos sociais passam a ser declarados. E se em alguns lugares levaram à contestação feita em relação ao Estado capitalista liberal, substituindo-o pelo Estado socialista, em outros, desta oposição resultou uma profunda modificação no Estado capitalista que, deixando de ser liberal, para que em um primeiro momento passasse ao reconhecimento destes direitos, posteriormente viesse a intervir nas relações sociais e econômicas para garanti-los e efetiva-los.

Sendo os direitos sociais, resultado de lutas derivadas do antagonismos de classe, é necessário saber-se, então, como é construída a formulação teórica que os absorve na categoria de cidadania, a qual está, a princípio, ligada a uma noção jurídico-política norteada pelo arcabouço ideológico capitalista e liberal, e portanto burguês.

Marshal (1967, p.76), analisando a sociedade inglesa, conclui que a cidadania, a qual trás implícita a idéia de igualdade, tem sido uma instituição em desenvolvimento desde

\footnotetext{
Lênin define classes sociais da seguinte forma: "As classes são grandes grupos de homens que se diferenciam entre si pela situação que ocupam num sistema de produção social, historicamente determinado, pelas relações em que se encontram relativamente aos meios de produção, pelo papel que desempenham na organização social do trabalho, e, consequentemente, pelo modo e pela proporção segundo os quais recebem a a parte da riqueza social de que dispõem. As classes sociais são grupos humanos, um dos quais pode apropriar-se do trabalho de outrem por ocupar posições diferentes num determinado regime de economia social."- Conforme tradução de Geraldo Simões Jr. in O Pensamento Vivo de Marx - São Paulo: Martins Claret Editores, 1986.
} 
a segunda metade do século XVII, e que seu crescimento coincide com o desenvolvimento do capitalismo, que é um sistema de desigualdade. Entende também que a existência de classes sociais traduz a desigualdade.

Portanto a identificação correta, determinante das relações sociais na sociedade capitalista é de existência de relações de desigualdade que dão suporte a antagonismos de classe. E a categoria cidadania tende a mostrar-se incompatível com a desigualdade capitalista.

Mas não é efetivamente o que se apresentou. O princípio de cidadania, não conflitou-se com o de classes sociais, e mais do que isto, acabou por justificar a desigualdade social do sistema capitalista.

O desenvolvimento simultâneo das duas categorias, classe social e cidadania, estabelece-se não em virtude do que traduzem, igualdade ou desigualdade, mas fundamentalmente por serem entendidas como instituições de origens distintas. As diferenças de classe, no sistema capitalista, não se estabelecem em leis, e costumes da sociedade $^{2}$, mas emergem da combinação de uma variedade de fatores relacionados com as instituições da propriedade, educação e estrutura econômica ${ }^{3}$. A cidadania, por sua vez, é estabelecida por uma determinação vinculada ao direito, é concedida aos que são membros integrais de uma comunidade, que são iguais em direitos e obrigações ${ }^{4}$.

Esta diversificação da natureza de ambas categorias é que permitiu a convivência em que a cidadania passa a legitimar a desigualdade, através do entendimento de que todos os homens sendo livres, tinham o igual direito de exercer a liberdade para goza-la plenamente. A desigualdade proveniente do exercício da liberdade individual, não foi preocupação encartada no conceito de cidadania, uma vez que esta decorre de um direito que pretendia-se natural, e aquela é uma situação derivada do exercício das relações comuns, entendidas estas como a forma que se utiliza a liberdade. A cidadania, lastreada inicialmente nos direitos civis, nunca se incompatibilizou com as desigualdades provocadas pelo sistema capitalista. Segundo observa Marshal (1967, p. 79)

\footnotetext{
2 Conforme ocorre em um tipo de classe que Marshal define como de espécies humanas distintas, hereditárias - patrícios, plebeus, servos e escravos. (MARSHAL, 1967, p.06)

3 (MARSHAL, 1967, p.77)

4 (MARSHAL, 1967, p.76)
} 


\begin{abstract}
Começando do ponto no qual todos os homens eram livres, em teoria, capazes de gozar de direitos, a cidadania se desenvolveu pelo enriquecimento do conjunto de direitos de que eram capazes de gozar. Mas êsses direitos não estavam em conflito com as desigualdades da sociedade capitalista; eram, ao contrário, necessários para a manutenção daquela determinada forma de desigualdade. A explicação reside no fato de que o núcleo da cidadania, nesta fase, se compunha de direitos civis. E os direitos civis eram indispensáveis, a uma economia de mercado competitivo. Davam a cada homem, como parte de seu status individual, o poder de participar, como uma unidade independente, na concorrência econômica, e tornaram possível negar-Ihes a proteção social com base na suposição de que o homem estava capacitado a proteger a si mesmo.
\end{abstract}

A trajetória da cidadania política, durante muito tempo ligada à cidadania civil, não modificou o quadro de desigualdade social existente durante os dois últimos séculos, e portanto também não fez oposição ao conceito de classe social. Mas a possibilidade aberta a partir da consolidação deste tipo de cidadania no século XX e a ampliação do sufrágio, antes censitário e masculino, e posteriormente universal, fez com que as reinvindicações de caráter social, declaradas nas lutas empreendidas no século XIX e XX passassem a ser positivadas nos ordenamentos jurídicos, dos quais a constituição de Weimar é exemplo clássico. Mas, em termos mundiais, tal positivação, pelo menos na primeira metade do século XX, não fora suficiente para dar garantia e efetividade a esses direitos.

Foram conquistas que forçaram o reconhecimento dos direitos sociais que acabaram por consolidar a denominada "cidadania social". Marshal (1967, p. 88-89), analisando exclusivamente a Inglaterra, indica a elevação da renda, a universalização da educação e abolição da indigência como traços da consolidação de uma cidadania social que não somente reduz a desigualdade social, mas que modifica todo o padrão do sistema econômico e social.

Marshal (1967, p. 103), chega ao entendimento de que a cidadania social, traçada na incorporação dos direitos sociais ao instituto de cidadania, fato ocorrido durante o século $X X$, fez com que surgisse um antagonismo entre cidadania e o sistema de classes sociais do capitalismo, e sugere um estado de guerra entre ambos, causando um forte impacto nas relações econômicas e sociais.

É importante ressaltar que Marshal (1967), em sua obra, não demonstra preocupação com a efetividade dos direitos sociais. Sua exposição faz a análise do desenvolvimento da cidadania tendo como pressuposto um conjunto de atos legislativos que identificam em cada momento histórico a afirmação dos direitos civis, políticos e sociais. 
Talvez essa falta de preocupação seja simplesmente decorrente do fato de que na Inglaterra as determinações legislativas são cumpridas, e de que o estado de bem estar social desenvolveu-se na Inglaterra através de uma participação ativa do parlamento em conjunto com a sociedade, cujas vontades talvez sejam únicas na garantia desses direitos.

No Brasil, uma possibilidade de consolidação dos direitos sociais, iniciados a partir da positivação na Constituição de 1934, sofrera duros reveses, que se iniciam como a própria derrubada desta Constituição três anos após, seguida de uma política paternalista e sufocadora dos anseios e lutas populares, realizada através da política populista implantada no Estado Novo, que teve sequência nos governos que se seguiram até 1964, culminando com o período de "sufocação sem paternalismo" do regime militar.

Somente a partir do mobilização empreendida a partir dos anos finais da ditadura militar e da promulgação da Constituição de 1988, foi possível à sociedade brasileira iniciar uma movimentação que tivesse por objeto a proclamação, a garantia e a efetividade de direitos sociais e políticos que se identifiquem com a denominada cidadania social presente da Europa através do Estado de Bem Estar Social levado a cabo no período que seguiu-se à Segunda Guerra Mundial.

Tal movimento traduziu-se na elaboração e proclamação da própria constituição, consagradora de direitos que fazem parte do arcabouço de conquistas da humanidade, particularmente no aspecto da ocidentalização. Os direitos sociais nela inscritos, seja diretamente ou através de princípios explícitos ou implícitos, denotam o seu caráter de vinculação à concepção de cidadania social pugnada pelas concepções que não são somente de Marshal, mas que derivam da construção da noção teórica e prática de igualdade social realizada no ocidente nos últimos cem anos.

Portanto, a Constituição Federal, ao proclamar direitos e garantias através de regras e princípios com forte conteúdo social, disseminados em todos os seus títulos e capítulos, que devem ser interpretados como sendo parte de um só sistema, adquiriu forma que a coloca na condição de reguladora e garantidora da cidadania social. E neste contexto, tornase ultrapassada e descomprometida com o anseio popular, a doutrina que pretende identificar o conceito de cidadania como mero exercício de direitos políticos ou mesmo civis, negando-lhe conteúdo mais abrangente e vinculando-o à uma perspectiva liberal. 


\section{A judicialização dos conflitos}

Aquele entendimento, que faz essa interpretação restritiva da cidadania, ou quando muito a estende ao exercício dos direitos individuais, mostra-se descomprometida com a possibilidade de efetivação dos direitos sociais inscritos na constituição, pois serve de marco teórico para a doutrina que pretende ver afastada do campo de atuação do poder judiciário a apreciação de conflitos gerados a partir da não aplicação das regras e princípios de direitos fundamentais disseminados no texto constitucional.

Ao mesmo tempo em que ampliaram-se os direitos sociais, através de lutas e conquistas, passou-se a exigir do estado uma maior intervenção na garantia dos mesmos, seja através do legislativo ou do executivo. Garantida a legislação, a sociedade busca agora a efetivação dos direitos sociais, e diante de um executivo limitado pelos acordos macroeconômicos e políticos, busca no judiciário, reconhecendo-o efetivamente como uma das instituições do poder estatal, a possibilidade de efetivação destes direitos.

Nesta busca pelo judiciário, como meio para solução dos conflitos sociais com vistas a dar consolidação à cidadania social, é possível identificar três tipos de contestação ou oposição alicerçadas em diferentes matrizes de interpretação e de ideologia. A primeira, de caráter jurídico-sociológico, entende que a procura pelo judiciário para resolução destes conflitos encontra obstáculo em questões ligadas à capacidade da tutela judicial para responder à demandas que dizem respeito a questões de eficácia de suas decisões, eficiência e acessibilidade ao sistema judicial ${ }^{5}$. A Segunda diz respeito a um posicionamento de caráter jurídico-ideológico que entende não ser tarefa do judiciário a resolução de tais conflitos. E faz parte de uma cultura jurídica que tem por objetivo impedir a discussão, o confronto e a tomada de decisão por parte do judiciário. A terceira, ligada a uma concepção políticoideológica entende que a judicialização dos conflitos sociais frustra a possibilidade de desenvolvimento das lutas populares pela reivindicação de direitos.

Na primeira concepção acima assinalada enquadram-se as teorias que surgem no âmbito do direito, que dizem respeito à existência de um direito que não é estatal, que se resolve nas comunidades, que é paralelo. Esta concepção, aliada à conformação de que o judiciário é incapaz de resolver questões ligadas ao exercício da cidadania social, leva à conclusão de que sua proposição, para resolução dos conflitos, é tão somente buscar o

\footnotetext{
5 Ver (SANTOS, 1996).
} 
exercício desta cidadania no seio da comunidade em seu sentido micrológico. Isto significaria a retirada e descompromisso estatal com a consolidação dos direitos sociais e colocaria os setores mais fracos da relação social em condições de subjugação aos setores comunitários mais organizados ou violentos.

A Segunda concepção, que não necessita de uma referência bibliográfica definida, pois encontra-se disseminada na cultura jurídica brasileira, e produz posicionamentos doutrinários como o enfocado no início, baseia-se em comandos que têm uma fonte epistemológica calçada em postulados jurídico-ideológicos, a qual forma uma cultura jurídica dominante que acaba por limitar a atuação do judiciário sob orientações que proíbem o juiz de julgar contra a lei e somente o fazem agir para reconstruir uma realidade que leve a subsunção de um fato a uma norma, sempre em conflitos que são particularizados, com a prevalência da garantia de direitos do indivíduo. Frente à existência desse aculturamento jurídico, não somente setores conservadores e mantenedores do status quo, mas também magistrados preparados e talhados nesta concepção jurídica têm-se mostrado avessos ou perplexos, às novas exigências que lhes são feitas, negando a tutela do judiciário as reclamos da sociedade para o efetivo exercício da sua cidadania.

O terceiro entendimento, destituído de qualquer enfoque jurídico, não contribui para a análise do problema abordado uma vez que não se preocupa com a postura que deve ser levada a cabo pelo Estado, face à demanda apresentada, mas tão somente propõe um deslocamento do campo onde trava-se a batalha pela consolidação dos direitos fundamentais. Nem mesmo preocupa-se em entender os motivos que levam à eleição das salas dos tribunais como arena de disputa por tais direitos, e por este motivo não deve ser tomada em consideração para o desenvolvimento do presente trabalho, o qual tem assente uma constatação para a qual procura-se uma resolução a ser dada pelo Estado.

Quanto às duas primeiras posições acima destacadas, está caracterizado que servem aos interesses dos que pretendem a manutenção da atual ordem de coisas. A partir do momento em que o estado, e particularmente o judiciário, dá suas costas aos conflitos sociais existentes, escudando-se em uma teoria positivista-liberal, ou justificam-se na sua inoperância passando a propor a resolução de conflitos fora do âmbito estatal, mantém-se a ordem da exclusão social e frusta-se a possibilidade de consolidação da cidadania social. 
A busca que a sociedade faz ao judiciário, para resolução de conflitos sociais e efetivação da sua cidadania não é fenômeno brasileiro. Ocorre nas chamadas democracias sociais. E o fato de o judiciário brasileiro deparar-se com esta exigência, aponta para a consolidação de nossas instituições democráticas e sociais. Tal expansão global do poder judiciário tem sido tratada sob o signo da "judicialization of politics", conforme definido por Tate e Vallinder (1995, p. 5), e que inclui também, como sugere a denominação, a decisão do poder judiciário sobre conflitos de ordem política, além daqueles de cunho social.

Sinteticamente poderíamos indicar dois motivos para esta busca do judiciário na consolidação da cidadania social: a) o excesso de leis definidoras direitos sociais, reguladas pela constituição ou nela inscrita diretamente, não mais justifica a simples luta parlamentar travada nas últimas décadas, uma vez que a positivação dos direitos já ocorrera, carecendo de efetividade; b) a consolidação das instituições democráticas sob uma ótica de defesa dos interesses das minorias, que para asseguramento de seus direitos, não podem contar somente com o parlamento ou outras instituições que efetivamente são controlados pela maioria.

Por estes motivos, o Poder Judiciário vem sendo chamado a desempenhar funções de garantir e dar efetividade à constituição, em questões sensíveis como o direito de minorias e de justiça distributiva. Através da atuação de partidos, sindicatos e sociedades civis, o Poder Judiciário passa a tornar-se parte fundamental na possibilidade de consolidação da cidadania social, confirmando as hipóteses de Tate e Vallinder (1995) ${ }^{6}$ sobre a judicialização da política como um recurso das minorias contra as maiorias parlamentares a que, no caso específico do Brasil, agrega-se o papel de decidir em matérias de política econômica e de justiça social.

Esta situação, que coloca o judiciário e seu papel emancipatório na "ordem do dia" não é uma situação que pode ser escolhida por juristas, governantes ou legisladores. A escolha que está sendo feita parte da própria sociedade, que bate às portas do Poder Judiciário exigindo resposta. Não é uma situação da qual se possa ter efetivo controle, como se fosse possível ao juiz simplesmente dizer que ao povo que: "fica do outro lado da praça" o lugar onde deve-se reclamar. O reclamante já "circulou pela praça" e não obteve a resposta. Agora é a vez do Judiciário.

$6 \quad$ Especialmente os capítulos 2 e 3. 
Garapon (1999, p. 227-228) indica a existência de uma nova concepção de Estado, onde a justiça é compelida a proporcionar materialmente e não apenas formalmente a igualdade de direitos, sugerindo que, se no século XIX, da ordem liberal, houvera uma preponderância do legislativo, e no século $X X$, sob a égide da providência, foi a vez do executivo, o século XXI caminha para ser o da supremacia do judiciário.

\section{Nova hermenêutica e nova jurisdição}

Para dar resposta a esta nova situação, concepções lógico-formais de direito, descomprometidas com a realização de justiça e consolidação da cidadania social, não cabem mais no mundo jurídico contemporâneo. O Poder Judiciário não pode mais ater-se à regra de aplicação de lei infra-constitucional aos fatos reclamados.

Com a constitucionalização de direitos sociais e coletivos, universalmente aceitos no mundo ocidental, que ligam o direito à ética e colocam a lei como fonte secundária do direito, a cultura jurídica que entende ser função dos juizes a aplicação de um mero vínculo lógico-formal de normas aos fatos torna-se deslocada da realidade exigida, e põe em xeque a função do Estado como modelo de sociedade política que possa atender os interesses da coletividade. Persistir nesse caminho, tal qual naquele que nega o recurso à justiça dizendo haver um direito que não é estatal, e que, portanto, nas comunidades devem resolver-se os problemas, criará uma crise institucional de dimensões ainda não previstas. Ou os magistrados assumem o papel de guardiões da constituição e garantidores da cidadania, ou no futuro, talvez próximo, o judiciário seja colocado no rol das instituições desacreditadas pela sociedade e termine como peça de retórica e legitimadora da desigualdade social.

O Poder Judiciário, não pode mais escudar-se na falsa idéia de neutralidade do juiz, que efetivamente não existe. Não é somente o magistrado que carrega uma carga ideológica derivada da sua condição de classe, e da sua experiência de vida. O Direito, que é instrumento, e não um fim dele próprio está, por sua própria condição, orientado pela ideologia política dos sistema ao qual serve e portanto fica subordinado às circunstâncias da atividade política.

Portanto, as decisões do Poder Judiciário repercutem políticamente e também socialmente, e isto não pode mais ser negado pelos membros da instituição. A não ser pelo compromisso com a cultura jurídica predominante, mantido por membros da comunidade 
jurídica, na atualidade, dificilmente encontraremos um setor da sociedade, que tenha a compreensão de que os julgados são totalmente destituídos de carga ideológica ou que sejam uma visão neutra das relações humanas. Ou seja, a subsunção do fato à norma válida, como método do direito e explicativo da solução de litígios, o qual não se preocupa com o caráter de justiça da decisão, não tem mais encontrado a subserviência de uma sociedade que, ao contrário, requer uma maior aproximação entre as decisões prolatadas pelos magistrados e o Estado Social.

Ao mesmo tempo em que se faz necessária a formação de uma nova cultura jurídica, lastreada em uma nova hermenêutica para a consolidação da cidadania social, não menos importante é a existência de uma jurisdição que possa ser sensível à modificação exigida.

O Poder Judiciário no decorrer de sua história no Brasil, tem se mostrado uma instituição anti-democrática, tanto internamente, quando não deixa claro para a sociedade as regras de promoção e provimento de cargos, como no seu contato e aproximação com a sociedade. É comum ouvir que o juiz é uma pessoa que deve manter-se reservada e sem contado direto com o público a fim de manter a sua imparcialidade. Torna-se, portanto, como é comum dizer, um ser anti-social. Isto também faz parte da cultura jurídica a que nos referimos. Esta postura tem-se refletido nos tribunais, onde a sociedade encontra-se alijada quanto ao conhecimento dos procedimentos e decisões e, com exceção da figura do amicus curiae $^{7}$ possibilitado em alguns procedimentos de jurisdição constitucional, cabe ressaltar que de forma deficiente, não existem mecanismos que coloquem o cidadão e o juiz num contato próximo em que este possa entender que aquilo que julga não são histórias descritas em um amontoado de papéis, mas possibilidades de vida que esperam a efetividade de uma justiça declarada, mas ainda não realizada.

\section{Conclusão}

Refletimos sobre, como a identificação do princípio de cidadania, vinculado a uma matriz liberal, ainda presente em nossa cultura jurídica, encontra-se avessa à ordem constitucional estabelecida no Brasil após a edição da constituição de 1988.

\footnotetext{
7 Lei no 9.882/99.
} 
Foi empreendida, a partir dos estudos de Marshal, uma análise sobre a trajetória da cidadania, constatando-se o surgimento do elemento social no século XIX, sendo possível concluir, a partir da leitura inglesa, que o século XX foi o da sua consolidação na Europa Central. E sugerimos que no Brasil a consolidação da cidadania social ainda é uma tarefa a se realizar.

Enfraquecidas as formas de reivindicação social através do diálogo parlamentar possibilitado pela cidadania política, através do qual se reconheceram direitos que foram positivados mas não adquiriram eficácia, e da constatação de que, muitas das vezes, é a própria atividade governamental realizada pelo executivo, que impede a consolidação dos direitos sociais. A sociedade, passa a incumbir o judiciário na tarefa de possibilitar a efetividade dos direitos sociais e realização da cidadania social.

Concepções, de matizes ideológicos diversos, tendem a negar ao judiciário a tarefa que the vem sendo atribuída, mas demonstram ignorar que a postura de negativa à sua realização podem levar à uma crise de legitimidade do Estado, pelo menos este que conhecemos, uma vez que a porta do tribunal é a última a ser procurada, e portanto a última possibilidade de encontrar-se a saída.

Conclui-se que, uma tomada de posição pelo judiciário, que leve em consideração a possibilidade de dar efetividade aos direitos sociais, deve ter em conta uma significativa modificação da cultura jurídica predominante, que abandone os critérios liberais e lógicoformalistas de interpretação e ligue o direito à ética e à justiça, e ao mesmo tempo construase uma jurisdição democrática que não se esconda do povo e de suas aspirações, mas encontre nele o argumento e sentido da existência do Estado e portanto, do próprio Poder Judiciário.

\section{Referências}

FERREIRA FILHO, Manoel Gonçalves. Curso de Direito Constitucional. 22. ed. atual. São Paulo: Saraiva, 1995. p. 99.

GARAPON, Antoine, O juiz e a democracia - Rio de Janeiro: Revan, 1999. p. 227.

MARHALL, T. H. Cidadania, Classe Social e Status. Rio de Janeiro: Zahar Editores, 1967. 
SANTOS, Boaventura Souza. Os Tribunais Nas Sociedades Contemporâneas. O caso português. - Portugal: Edições Afrontamento, 1996.

SIMÕES JR., Geraldo.O Pensamento Vivo de Marx. São Paulo: Martins Claret Editores, 1986.

VALLINDER, Torbjöm; TATE, Neal, The Global Expansion of Judicial Power. New York: University Press, 1995. p. 5. 